\title{
Postnatal Rosiglitazone Administration to Neonatal Rat Pups Does Not Alter the Young Adult Metabolic Phenotype
}

\author{
Nghia C. Truong Afshan Abbasi Reiko Sakurai W.N. Paul Lee John S. Torday \\ Virender K. Rehan \\ Department of Pediatrics, David Geffen School of Medicine, University of California at Los Angeles, \\ Torrance, Calif., USA
}

Rosiglitazone $\cdot$ Lung development $\cdot$ Peroxisome

proliferator-activated receptor- $\gamma \cdot$ Fetal programming

\section{Key Words}

mental metabolic programming or lead to an altered metabolic phenotype in the young adult, further re-enforcing the safety of PPAR $\gamma$ agonists as a novel lung-protective strategy.

Copyright $\odot 2011$ S. Karger AG, Basel

\begin{abstract}
Background: Rosiglitazone (RGZ), a peroxisome proliferator-activated receptor- $\gamma$ (PPAR $\gamma$ ) agonist, significantly enhances lung maturation without affecting blood biochemical and metabolic profiles in the newborn period. However, whether this exposure to RGZ in neonatal life alters the adult metabolic phenotype is not known. Objective: To determine the effects of early postnatal administration of RGZ on the young adult metabolic phenotype. Methods: Newborn rat pups were administered either saline or RGZ for the first 7 days of life. At 11-14 weeks, glucose and insulin tolerance tests and deuterium labeling were performed. Blood and tissues were analyzed for various metabolic parameters. $\boldsymbol{R e}$ sults: Overall, there was no effect of early postnatal RGZ administration on young adult body weight, glucose and insulin tolerance, plasma cholesterol and triglyceride profiles, insulin, glucagon, cardiac troponin, fatty acid synthesis, or tissue adipogenic differentiation. Conclusions: Treatment with RGZ in early neonatal life does not alter later develop-
\end{abstract}

\section{Introduction}

Peroxisome proliferator-activated receptor- $\gamma$ (PPAR $\gamma)$, a ligand-activated transcription factor that belongs to the superfamily of nuclear hormone receptors, is essential for lipid homeostasis in several tissues, including the lung [ 1 , 2]. In normal lung development, it has a critical role in stimulating the alveolar epithelial-mesenchymal paracrine signaling pathway $[3,4]$. Using a neonatal rat model, it was recently shown that systemically administered rosiglitazone (RGZ), a selective PPAR $\gamma$ agonist, for up to 7 days of life significantly enhances lung maturation without significantly affecting serum electrolytes, blood glucose, blood gases or the serum lipid profile in the newborn period [5]. However, there is very limited information on long-term effects of exposure to PPAR $y$ agonists in the newborn period. Recently, food restriction studies in rats have shown that early administration of the PPAR $\gamma$

\section{KARGER}

두 2011 S. Karger AG, Basel

Fax +41613061234

E-Mail karger@karger.ch

www.karger.com www.karger.com/neo
Virender K. Rehan, MD, Department of Pediatrics

Los Angeles Biomedical Research Institute at Harbor-UCLA Medical Center

David Geffen School of Medicine at UCLA

1124 West Carson Street, Torrance, CA 90502 (USA)

Tel. +1 310222 1965, E-Mail vrehan@labiomed.org 
agonist RGZ reversed postnatal growth-restricted offspring back to their normal metabolic state [6]. Since PPAR $\gamma$ agonist administration has recently been suggested as a potential intervention to enhance neonatal lung maturation, it is important to determine the safety of PPAR $\gamma$ agonists when given therapeutically. This is particularly so since the other therapeutic agents that have been used to promote lung maturation, such as steroids and all-trans retinoic acid, have significant limitations and side effects [7-10].

In this study, using a rat model, we have examined the effects of the systemically administered PPAR $\gamma$ agonist RGZ for up to the first 7 days of postnatal life on selected markers of lung differentiation and metabolic programming of the treated animals as young adults. Since we have previously shown that RGZ exposure does not significantly affect the blood biochemical and metabolic profiles in the newborn period [5], we hypothesized that a PPAR $\gamma$ agonist given systemically at doses optimized to accelerate lung development would not significantly alter the metabolic profile and phenotype in young adult animals. The effects of systemically administered RGZ on the metabolic profile were assessed by measuring body weight, glucose tolerance, insulin tolerance, de novo fatty acid synthesis and plasma troponin I, cholesterol, triglycerides, insulin and glucagon levels. Lung maturation was assessed by determining lung morphometry and various molecular and functional determinants of lung maturation.

\section{Materials and Methods}

\section{Animal Protocol}

Time-mated, first-time pregnant Sprague Dawley rats (200$220 \mathrm{~g}$ ) were obtained at day 16 of gestation, and were allowed to acclimatize in humidity- and temperature-controlled rooms on a 12-hour:12-hour light:dark cycle, and were allowed food and water ad libitum. On day 22 of pregnancy, the dams spontaneously delivered between 11-14 pups per dam. To prevent the confounding effects of variable litter size, the number of pups/dam was kept constant $(=8)$ by culling the extra pups within $2 \mathrm{~h}$ after birth. Newborn pups receiving RGZ were divided into the following four groups: control, $0.3,1$ and $3 \mathrm{mg} / \mathrm{kg}$ body weight. A total of 14 animals were studied in each group, with a minimum of 4 males and 4 females and 3 litters for each group. The diluent (saline) or RGZ (Cayman Chemicals, Ann Arbor, Mich., USA) was administered intraperitoneally in 100 - $\mu$ l volumes once daily for 7 days, postnatally, as in our previous study [5]. The first dose of RGZ was administered within $2 \mathrm{~h}$ after delivery. Pups were breast-fed ad libitum and then weaned to rat chow on postnatal day 21. Glucose tolerance and insulin tolerance tests were performed at 11-12 weeks of age. To perform these studies, either glucose or insulin was administered after an overnight fast. In a subset of animals ( $\mathrm{n}=6$ for each group; 3 males, 3 females) at 14 weeks, de novo fatty acid synthesis and incorporation into tissues were analyzed by deuterium labeling and mass spectrometry as previously described [11]. Animals received deuterated water (99.9\%) prepared in normal saline in an amount equal to about $4 \%$ of body weight, intraperitoneally, and then were given free access to drinking water containing $6 \% \mathrm{D}_{2} \mathrm{O}$ for 7 days.

At 14 weeks, the rats were euthanized and the lungs collected and flash-frozen for later Western hybridization and morphometry. To determine the effects of systemically administered RGZ on PPAR $\gamma$ and its downstream target adipocyte differentiationrelated protein (ADRP) expression in liver, peritoneal fat and subcutaneous fat were also determined. Blood was collected by cardiac puncture from each animal and either processed immediately for glucose analysis, or frozen at $-80^{\circ} \mathrm{C}$ for later determination of cholesterol, triglyceride, glucagon, insulin, cardiac troponin and fatty acids. All animal procedures were performed following the National Institutes of Health guidelines for the care and use of laboratory animals and approved by the Institute's Animal Care and Use Committee.

\section{Western Blot Analysis}

Western analysis was performed as described previously [12].

\section{Lamellar Body Staining}

P180 lamellar body protein expression was assessed by immunofluorescence staining as described by us previously [5].

\section{Glucose and Insulin Tolerance Tests}

Either glucose ( $1 \mathrm{~g} / \mathrm{kg}$ body weight, intraperitoneally) or insulin (1 unit $/ \mathrm{kg}$, subcutaneously) was administered after an overnight fast. Glucose was assayed at various time points $(0,15,30$, 60, 120 and $180 \mathrm{~min}$ ), using a glucometer (Home Diagnostics, Fort Lauderdale, Fla., USA), according to the manufacturer's protocol.

Plasma Cholesterol and Triglyceride Determination

Cholesterol and triglycerides were measured by enzymatic methods, using the Raichem kit (Cliniqa Corporation, San Marcos, Calif., USA) for cholesterol (dynamic range: 0-600 mg/dl; intra-assay coefficient of variation: 1.7\%), and Caymen kit (Caymen Chemical Company, Ann Arbor, Mich., USA) for triglycerides (dynamic range: $0-200 \mathrm{mg} / \mathrm{dl}$; intra-assay coefficient of variation: $1.34 \%$ ), following the manufacturer's protocol.

Plasma Insulin and Glucagon

Insulin was measured with an ELISA kit (detection limit of 0.2 $\mathrm{ng} / \mathrm{ml}$ and $100 \%$ specificity) and glucagon by a RIA kit (Linco Research, St. Charles, Mo., USA; detection limit: 20 pg/ml; crossreactivity to oxyntomodulin: $<0.1 \%)$.

Measurement of Plasma Cardiac Troponin I Levels

Plasma cardiac troponin I levels were determined by a rat cardiac Tn-I ELISA kit (Cat. No. 2010-2-HSP; Life Diagnostics, West Chester, Pa., USA; detection limit: 0.156 ng/ml; specificity: 100\%).

Determination of Choline Incorporation into Disaturated

Phosphatidylcholine and Triolein Uptake

Choline incorporation into disaturated phosphatidylcholine and triolein uptake, two key markers of alveolar function, were determined as described previously $[5,12]$. 


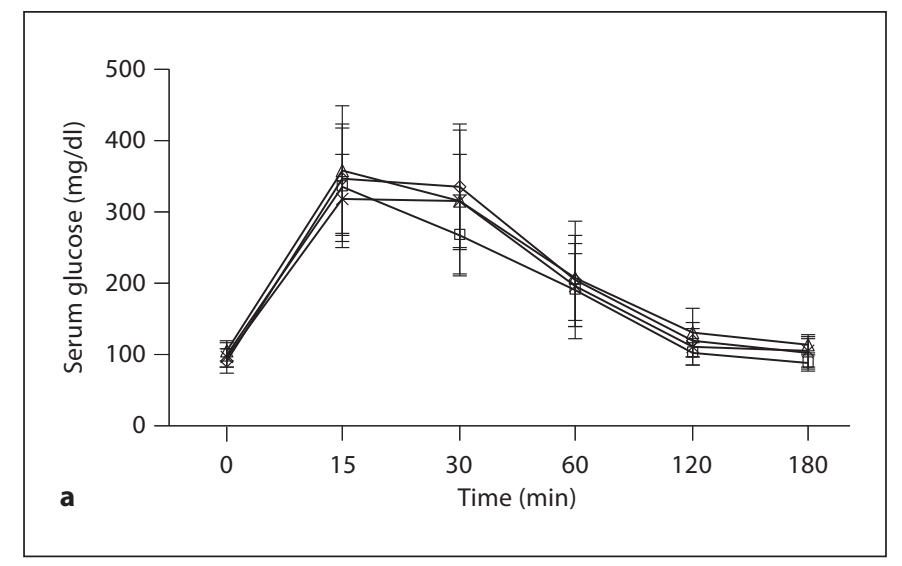

Fig. 1. a Effect of RGZ on glucose tolerance test: at 11 weeks of age, glucose was administered at $1 \mathrm{~g} / \mathrm{kg}$ body weight intraperitoneally after an overnight fast. Glucose was assayed at time 0 (baseline), $15,30,60,120$ and $180 \mathrm{~min}$. There were no significant differences $(\mathrm{p}>0.05)$ in timed serum glucose values in the treated groups compared with controls during the GTT. b Effect of RGZ on insulin tolerance test: at 12 weeks of age, insulin was administered

\section{Lung Morphometry}

Radial alveolar counts were determined by an investigator unaware of the treatment groups following the method described previously [5].

\section{Statistical Analysis}

ANOVA and a two-tailed Student $t$ test with Bonferroni correction for multiple comparisons were used to analyze the experimental data. $\mathrm{p}$ values $<0.05$ were considered to be statistically significant.

\section{Results}

\section{Effect of RGZ on Body Weight}

Body weight is a reflection of overall metabolism, so the effect of RGZ on body weight was determined. There were no significant differences in body weight (grams) at birth $(6.9 \pm 0.8,7.2 \pm 0.8,6.9 \pm 0.6$, and $7.3 \pm 0.7$ for control, RGZ $0.3 \mathrm{mg} / \mathrm{kg}$, RGZ $1 \mathrm{mg} / \mathrm{kg}$, and RGZ $3 \mathrm{mg} / \mathrm{kg}$ groups, respectively), 11 weeks (318 $\pm 65,300$ $\pm 63,302 \pm 84$, and $314 \pm 6$ for control, RGZ $0.3 \mathrm{mg} /$ $\mathrm{kg}$, RGZ $1 \mathrm{mg} / \mathrm{kg}$, and RGZ $3 \mathrm{mg} / \mathrm{kg}$ groups, respectively), and 14 weeks ( $423 \pm 118,403 \pm 106,411 \pm 137$, and $420 \pm 130$ for control, RGZ $0.3 \mathrm{mg} / \mathrm{kg}$, RGZ $1 \mathrm{mg} / \mathrm{kg}$, and RGZ $3 \mathrm{mg} / \mathrm{kg}$ groups, respectively) in the controls compared with treated groups. Values are means \pm SDs $(\mathrm{n}=56)$.

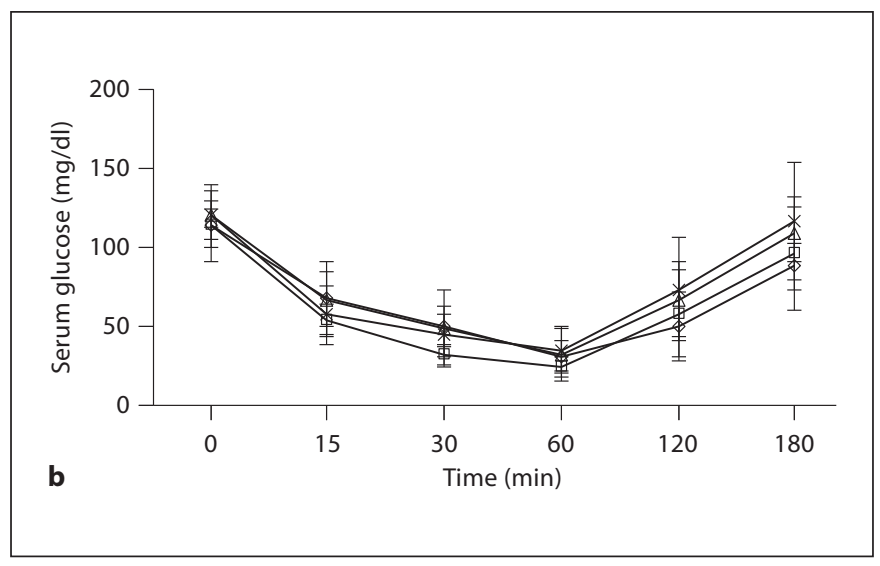

at 1 unit/kg body weight subcutaneously after an overnight fast. Glucose was assayed at time 0 (baseline), 15, 30, 60, 120 and 180 min. There were no significant differences $(p>0.05)$ in timed serum glucose values between the treated and control groups during the ITT. $\mathbf{a}, \mathbf{b} \diamond=$ Control group, $\square=\mathrm{RGZ} 0.3 \mathrm{mg} / \mathrm{kg}$ group, $\triangle=\mathrm{RGZ} 1 \mathrm{mg} / \mathrm{kg}$ group, $\times=\mathrm{RGZ} 3 \mathrm{mg} / \mathrm{kg}$ group.

\section{Effect of RGZ on Glucose Tolerance Test and Insulin} Tolerance Test

Because RGZ is used as a potent antidiabetic agent in adults, we determined its effects on glucose homeostasis using glucose and insulin tolerance tests (fig. 1). There were no significant effects at 11-12 weeks of age for any of the doses of RGZ examined.

\section{Effect of RGZ on Insulin, Glucagon and Cardiac}

Troponin Levels

There were no significant differences in insulin, glucagon or troponin I levels in the control group compared with the RGZ-treated groups (table 1). Please note that cardiac troponin I was detected in all plasma samples examined. This was an unexpected finding that we attributed to the cardiac puncture performed to collect blood at the time of animal sacrifice. This assumption is supported by significantly lower troponin I levels detected in the blood obtained from tail vein samples collected from the same animals before their sacrifice $(\mathrm{p}<0.05$, cardiac puncture vs. tail vein samples). Tail blood samples for the RGZ $0.3 \mathrm{mg} / \mathrm{kg}$ group were lost due to freezer malfunction and therefore could not be processed.

Effect of RGZ on Blood Cholesterol, Triglyceride Levels and Fatty Acid Synthesis

There were no significant differences in blood cholesterol and triglyceride levels and in the fraction of de novo 
Table 1. Plasma hormone and troponin measurements

\begin{tabular}{lllll}
\hline $\begin{array}{l}\text { RGZ } \\
\mathrm{mg} / \mathrm{kg}\end{array}$ & $\begin{array}{l}\text { Insulin } \\
\mathrm{ng} / \mathrm{ml}\end{array}$ & $\begin{array}{l}\text { Glucagon } \\
\mathrm{pg} / \mathrm{ml}\end{array}$ & $\begin{array}{l}\text { Troponin I, ng/ml } \\
\text { (sample obtained } \\
\text { via cardiac puncture) }\end{array}$ & $\begin{array}{l}\text { Troponin I, ng/ml } \\
\text { (sample obtained } \\
\text { via tail vein) }\end{array}$ \\
\hline 0 & $3.4 \pm 1.7$ & $235 \pm 54$ & $7.5 \pm 6.3$ & $0.8 \pm 0.5^{*}$ \\
0.3 & $2.6 \pm 1.5$ & $201 \pm 30$ & $7 \pm 4.8$ & $1.7 \pm 1.6^{*}$ \\
1 & $2.6 \pm 1.6$ & $229 \pm 56$ & $10.3 \pm 9$ & - \\
3 & $4.4 \pm 1.6$ & $180 \pm 33$ & $13.8 \pm 7.6$ & $0.8 \pm 0.5^{*}$ \\
\hline
\end{tabular}

There were no significant differences in hormone and troponin measurements in the treated groups compared with controls. There were no significant differences in insulin, glucagon or troponin I levels between groups. However, the troponin I levels in blood collected by cardiac puncture were significantly higher compared with the levels in blood collected via the tail vein $\left({ }^{*} \mathrm{p}<\right.$ 0.05 ). Tail blood samples for the RGZ $0.3 \mathrm{mg} / \mathrm{kg}$ group were not available for this analysis. Values are means \pm SDs ( $\mathrm{n}=33$ adults).

Table 2. Effect on plasma lipids and fatty acid synthesis

\begin{tabular}{llllll}
\hline $\begin{array}{l}\text { RGZ } \\
\mathrm{mg} / \mathrm{kg}\end{array}$ & $\begin{array}{l}\text { Cholesterol } \\
\mathrm{mg} / \mathrm{dl}\end{array}$ & $\begin{array}{l}\text { Triglyceride } \\
\mathrm{mg} / \mathrm{dl}\end{array}$ & $\mathrm{m} 2 / \mathrm{ml}$ & $\begin{array}{l}\text { Deuterium } \\
\text { enrichment }\end{array}$ & $\begin{array}{l}\text { Fraction of } \\
\text { new palmitate } \\
\text { molecules }\end{array}$ \\
\hline 0 & $105 \pm 23$ & $71 \pm 24$ & 0.447 & 0.0428 & 0.277 \\
0.3 & $98 \pm 9.6$ & $72 \pm 31$ & 0.434 & 0.0416 & 0.278 \\
1 & $101 \pm 13.6$ & $74 \pm 34$ & 0.439 & 0.0421 & 0.323 \\
3 & $100 \pm 6$ & $70 \pm 27$ & 0.431 & 0.0413 & 0.247 \\
\hline
\end{tabular}

There were no significant differences $(\mathrm{p}>0.05)$ in plasma cholesterol and triglyceride levels in the treated groups compared with the controls. Values are means \pm SDs ( $n=33$ adults). In a subset of animals ( $n=6$ for each group; 3 males, 3 females), the fraction of de novo lipogenesis and incorporation into the tissues were analyzed by deuterium labeling and mass spectrometry. There were no significant differences $(p>0.05)$ in the fraction of de novo synthesis of palmitate molecules in the treated groups compared with the controls. $\mathrm{m} 1=$ Fraction of isotopomer molecules with 1 deuterium substitution; $\mathrm{m} 2=$ fraction of isotopomer molecules with 2 deuterium atoms ( $\mathrm{n}=24$ adults).

Fig. 2. Effect of RGZ on lung maturation: the newborn rat pups were administered either diluent or RGZ in graded doses in 100$\mu \mathrm{l}$ volumes once daily intraperitoneally for 7 days, and then lung maturation was assessed at 14 weeks of age by determining the alveolar count and selective markers of alveolar epithelial (choline incorporation into disaturated phosphatidylcholine by lung explants and lamellar body and surfactant protein B and C immunostaining) and mesenchymal (triolein uptake by lung explants and protein levels of PPAR $\gamma$ and ADRP) differentiation. There synthesis of palmitate molecules (table 2) in the control group compared with the RGZ-treated groups.

\section{Effect of RGZ on Lung Maturation}

When examined at 14 weeks of age, there were no significant differences in the alveolar count, triolein uptake, choline incorporation into disaturated phosphatidylcholine (fig. 2a), and previously well-established markers of alveolar mesenchymal (PPAR $\gamma$ and ADRP; fig. 2b) and epithelial (lamellar body and surfactant protein B and C immunostaining; fig. 2c) differentiation between the groups.

\section{Effect of RGZ on PPAR $\gamma$ and ADRP Expression in}

Liver, Peritoneal Fat and Subcutaneous Fat

Because the PPAR $\gamma$ gene is expressed in a wide range of tissues [13], we next surveyed the effect of systemically administered RGZ on PPAR $\gamma$ and ADRP expression in selected extrapulmonary PPAR $\gamma$-expressing tissues, namely liver, peritoneal fat and subcutaneous fat. In general, 7 days of systemic administration of RGZ did not increase PPAR $\gamma$ or ADRP expression in liver, peritoneal fat or subcutaneous fat (fig. 3).

\section{Discussion}

Decades of research have focused on advancing pulmonary immaturity since it is the primary cause for the premature infant's significantly increased risk of adverse events. Antenatal steroids have been the prevailing standard of care for antenatal enhancement of lung maturity, significantly improving morbidity and mortality associated with prematurity $[7,14]$. However, systematic review of the literature shows that there is no postnatal intervention that has reliably enhanced pulmonary maturity, and that there remains considerable concern regarding the risk of adverse long-term neurodevelopmental outcomes in infants treated with postnatal steroids, precluding

were no significant differences in the alveolar counts, triolein uptake, choline incorporation into disaturated phosphatidylcholine (a), and markers of alveolar mesenchymal (PPAR $\gamma$ and ADRP, b, representative Western blots and the corresponding density histograms normalized to GAPDH are shown) and epithelial (lamellar body and surfactant protein $\mathrm{B}$ and $\mathrm{C}$ immunostaining, c, representative images are shown) differentiation between the groups. 


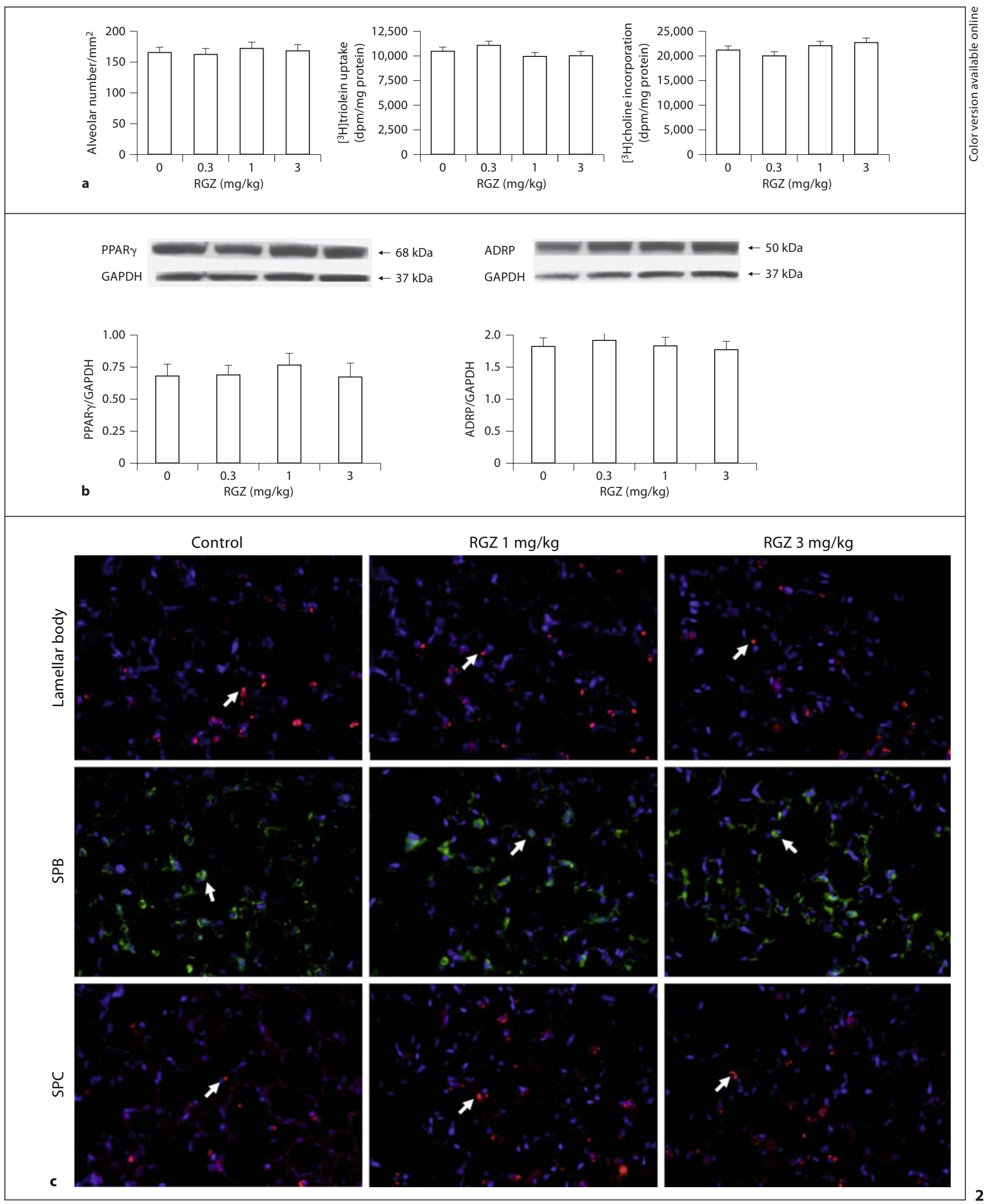

Metabolic Effects of Postnatal

Neonatology 2012;101:217-224 


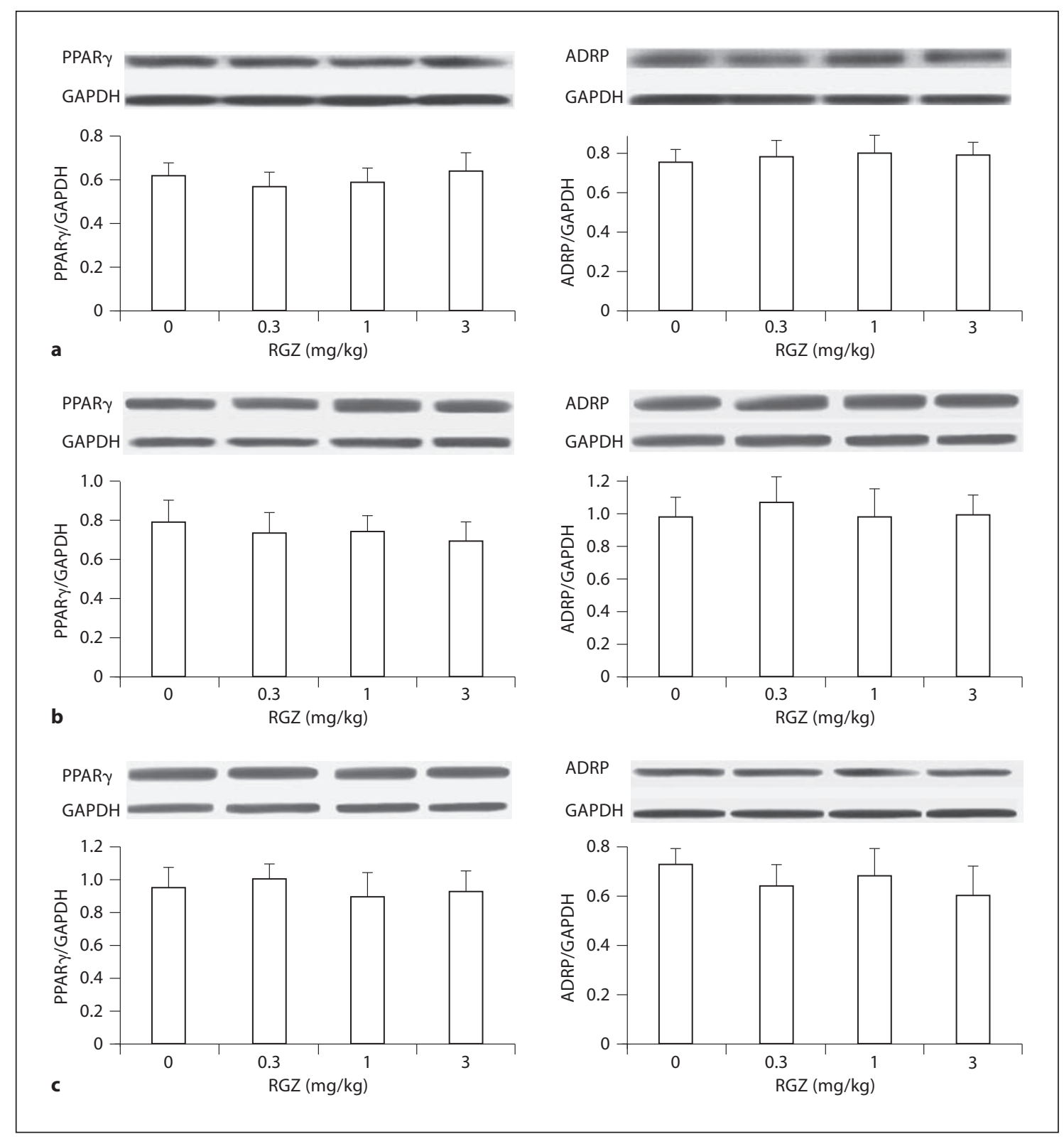

Fig. 3. Effect of RGZ on PPAR $\gamma$ and ADRP expression in liver, peritoneal and subcutaneous adipose tissue: the newborn rat pups were administered either diluent or RGZ in graded doses in 100 $\mu \mathrm{l}$ volumes once daily intraperitoneally for 7 days, and then PPAR $\gamma$ and ADRP expression were examined in the whole tissue lysates of the liver (a), peritoneal fat (b) and subcutaneous fat (c).
There were no significant differences $(\mathrm{p}>0.05)$ in protein levels of PPAR $\gamma$ or ADRP in the liver, or the peritoneal or subcutaneous fat, normalized to GAPDH, as determined by Western hybridization in the treated groups compared with the controls. Representative Western blots and the corresponding density histograms are shown. their routine use [15]. Our recent work has suggested PPAR $\gamma$ agonist administration as a possible intervention to enhance postnatal lung maturation, but the long-term safety of this intervention has not been determined. Having previously determined the safety of this intervention in the immediate newborn period [5], this study was focused on the safety of neonatal PPAR $\gamma$ agonist administration up to the young adult stage.

Since PPAR $\gamma$ activation has an important role in the transcription of insulin-responsive genes involving the 
control of glucose production, transport and utilization, we studied whether the administration of RGZ in the newborn period would affect body weight, glucose and insulin tolerance, glucagon and insulin levels in young adult rats. It is reassuring to note that daily doses of RGZ to neonatal rat pups for up to 7 days did not cause any significant changes in these parameters. Moreover, since PPAR $\gamma$-responsive genes are involved in regulating lipid metabolism, and have effects on plasma lipid profiles with long-term use in adults $[16,17]$, we studied the effect of RGZ administration for 7 days to neonatal rat pups on blood levels of cholesterol, total triglyceride, and on fatty acid synthesis, but did not find any significant effects on these parameters. In addition, because RGZ may increase the risk of heart failure in adults $[18,19]$, we examined its effect on plasma cardiac troponin I levels, which are well-established biomarkers of cardiac injury. Our study showed no significant differences in cardiac troponin I levels between the control and RGZ-treated animals in samples obtained by either cardiac puncture or via the tail vein method. However, the values were significantly higher in samples obtained by the cardiac puncture method versus the tail vein method. This difference is likely due to the cardiac trauma from cardiac puncture performed to obtain a blood sample in contrast to no direct cardiac trauma while obtaining a tail vein sample. Although our study did not show significant differences between the control and treated groups, the sample size in each group was not large enough to assess gender-specific differences. However, since 11-14 weeks postnatal age in the rat corresponds chronologically to a young human adult and since the metabolic syndrome may not manifest itself until middle age [20], i.e. 45 years in humans, which corresponds to approximately 18 months in the rat, the metabolic changes starting in mid-life may not be picked up by examining rats up to 14 weeks of postnatal age.
Although there are several PPAR $\gamma$ agonists available, we studied the synthetic thiazolidinedione compound RGZ due to extensive clinical experience with this drug [21]. The number of days and dose range of RGZ used in this study were based upon our previous studies and that of others [5, 22-25]. However, we emphasize that RGZ was studied only as a prototype for PPAR $\gamma$ agonists, and its safety and efficacy in human infants have not yet been documented.

In summary, there were no significant effects of early postnatal RGZ administration on body weight, glucose and insulin tolerance, plasma cholesterol or triglyceride levels, insulin, glucagon, cardiac troponin, or fatty acid synthesis and incorporation into tissues, suggesting that systemically administered RGZ does not significantly affect metabolic profiles in adulthood. This study also showed that there were no effects on any molecular and functional markers of lung maturation examined at 14 weeks of life. In addition, there were no significant differences in the expression of PPAR $\gamma$ and ADRP in any of the PPAR $\gamma$-expressing extrapulmonary tissues examined. Based on these findings, we conclude that treatment with the PPAR $y$ agonist RGZ in early neonatal life does not alter developmental metabolic programming, and does not lead to an altered metabolic phenotype in the young adult, further re-enforcing the safe use of PPAR $\gamma$ agonists as a novel lung-protective strategy. Further neonatal safety, pharmacokinetic and pharmacodynamic studies of this class of drugs need to be performed before PPAR $\gamma$ agonists can be considered for human trials for enhancing neonatal lung maturation.

\section{Acknowledgements}

This study was supported by grants from the NIH (HL075405, HL55268, HD51857, HD058948) and the TRDRP (15IT-0250 and 17R-0170).

\section{References}

1 Chen H, Jackson S, Doro M, McGowan S: Perinatal expression of genes that may participate in lipid metabolism by lipid-laden lung fibroblasts. J Lipid Res 1998;39:24832492.

-2 Tontonoz P, Hu E, Spiegelman BM: Regulation of adipocyte gene expression and differentiation by peroxisome proliferator activated receptor gamma. Curr Opin Genet Dev 1995;5:571-576.

\footnotetext{
- 3 Simon DM, Arikan MC, Srisuma S, Bhattacharya S, Tsai LW, Ingenito EP, Gonzalez F, Shapiro SD, Mariani TJ: Epithelial cell PPAR $\gamma$ contributes to normal lung maturation. FASEB J 2006;20:1507-1509.

$\checkmark 4$ Torday JS, Torres E, Rehan VK: The role of fibroblast transdifferentiation in lung epithelial cell proliferation, differentiation, and repair in vitro. Pediatr Pathol Mol Med 2003; 22:189-207.
}

5 Wang Y, Santos J, Sakurai R, Shin E, Cerny L, Torday JS, Rehan VK: Peroxisome proliferator-activated receptor gamma agonists enhance lung maturation in a neonatal rat model. Pediatr Res 2009;65:150-155.

6 Garg M, Thamotharan M, Pan G, Lee PW, Devaskar SU: Early exposure of the pregestational intrauterine and postnatal growth-restricted female offspring to a peroxisome proliferator-activated receptor- $\gamma$ agonist. Am J Physiol Endocrinol Metab 2010; 298:E489-E498. 
$>7$ Effect of corticosteroids for fetal maturation on perinatal outcomes. NIH Consensus Development Panel on the Effect of Corticosteroids for Fetal Maturation on Perinatal Outcomes. JAMA 1995;273:413-418.

8 Ballard PL, Ballard RA, Granberg JP, Sniderman S, Gluckman PD, Kaplan SL, Grumbach MM: Fetal sex and prenatal betamethasone therapy. J Pediatr 1980;97:451-454.

-9 Wapner RJ, Sorokin Y, Mele L, Johnson F, Dudley DJ, Spong CY, Peaceman AM, Leveno KJ, Malone F, Caritis SN, Mercer B, Harper M, Rouse DJ, Thorp JM, Ramin S, Carpenter MW, Gabbe SG: Long-term outcomes after repeat doses of antenatal corticosteroids. N Engl J Med 2007;357:11901198.

-10 Willet KE, Jobe AH, Ikegami M, Newnham J, Sly PD: Antenatal retinoic acid does not alter alveolization or postnatal lung function in preterm sheep. Eur Respir J 2000;16:101107.

-11 Lee WN, Bassilian S, Ajie HO, Schoeller DA, Edmond J, Bergner EA, Byerley LO: In vivo measurement of fatty acids and cholesterol synthesis using $\mathrm{D}_{2} \mathrm{O}$ and mass isotopomer analysis. Am J Physiol 1994;266:E699-E708.

-12 Rehan VK, Wang Y, Sugano S, Santos J, Patel S, Sakurai R, Boros LG, Lee WP, Torday JS: In utero nicotine exposure alters fetal rat lung alveolar type II cell proliferation, differentiation, and metabolism. Am J Physiol Lung Cell Mol Physiol 2007;292:L323-L333.
13 Tontonoz P, Spiegelman BM: Fat and beyond: the diverse biology of PPAR $\gamma$. Annu Rev Biochem 2008;77:289-312.

14 Roberts D, Dalziel S: Antenatal corticosteroids for accelerating fetal lung maturation for women at risk of preterm birth. Cochrane Database Syst Rev 2006;3:CD004454.

15 Cerny L, Torday JS, Rehan VK: Prevention and treatment of bronchopulmonary dysplasia: contemporary status and future outlook. Lung 2008;186:75-89.

16 Khan MA, St Peter JV, Xue JL: A prospective, randomized comparison of the metabolic effects of pioglitazone or rosiglitazone in patients with type 2 diabetes who were previously treated with troglitazone. Diabetes Care 2002;25:708-711.

17 Olansky L, Marchetti A, Lau H: Multicenter retrospective assessment of thiazolidinedione monotherapy and combination therapy in patients with type 2 diabetes: comparative subgroup analyses of glycemic control and blood lipid levels. Clin Ther 2003;25(suppl B):B64-B80.

18 Komajda M, McMurray JJ, Beck-Nielsen H, Gomis R, Hanefeld M, Pocock SJ, Curtis PS, Jones NP, Home PD: Heart failure events with rosiglitazone in type 2 diabetes: data from the RECORD clinical trial. Eur Heart J 2010;31:824-831.

19 Nissen SE, Wolski K: Rosiglitazone revisited: an updated meta-analysis of risk for myocardial infarction and cardiovascular mortality. Arch Intern Med 2010;170:1191-1201.

20 Grundy SM: Metabolic syndrome pandemic. Arterioscler Thromb Vasc Biol 2008;28:629636.
21 Standiford TJ, Keshamouni VG, Reddy RC: Peroxisome proliferator-activated receptor$\gamma$ as a regulator of lung inflammation and repair. Proc Am Thorac Soc 2005;2:226231.

22 Genovese T, Cuzzocrea S, Di Paola R, Mazzon E, Mastruzzo C, Catalano P, Sortino M, Crimi N, Caputi AP, Thiemermann C, Vancheri C: Effect of rosiglitazone and 15-deoxy- $\delta 12,14$-prostaglandin J2 on bleomycininduced lung injury. Eur Respir J 2005;25: 225-234.

23 Liu D, Zeng BX, Zhang SH, Yao SL: Rosiglitazone, an agonist of peroxisome proliferator-activated receptor gamma, reduces pulmonary inflammatory response in a rat model of endotoxemia. Inflamm Res 2005; 54:464-470.

24 Wayman NS, Hattori Y, McDonald MC, Mota-Filipe H, Cuzzocrea S, Pisano B, Chatterjee PK, Thiemermann C: Ligands of the peroxisome proliferator-activated receptors (PPAR-gamma and PPAR- $\alpha$ ) reduce myocardial infarct size. FASEB J 2002;16:10271040.

25 Dasgupta C, Sakurai R, Wang Y, Guo P, Ambalavanan N, Torday JS, Rehan VK: Hyperoxia-induced neonatal rat lung injury involves activation of TGF- $\beta$ and Wnt signaling and is protected by rosiglitazone. Am J Physiol Lung Cell Mol Physiol 2009; 296:L1031-L1041. 